\title{
Progression and regression of cervical lesions
}

\section{Review of smears from women followed without initial biopsy or treatment}

\author{
AI SPRIGGS* AND MM BODDINGTON† \\ From the Laboratories of Clinical Cytology, *Churchill Hospital, Oxford, and †Royal Berks Hospital, \\ Reading, UK
}

SUMMARY Cervical smears were reviewed from patients in whom a cytological abnormality was followed, after an interval without interference, either by regression to 'negative' or else by progression to invasive carcinoma. Twenty-eight cases were from a previously analysed series with positive smears and an interval of at least two years before investigation, resulting from refusal or failure to trace. Slides were also reviewed from 25 cases in which 'positive' smears had regressed to negative without escaping from surveillance, and from 10 patients subsequently developing invasive carcinoma whose previous slides, taken several years earlier, showed abnormalities on review. None of these 63 patients had any biopsy or other surgical procedure to the cervix between the initial smear and the outcome.

Slides showing 'superficial cell dyskaryosis' and/or well-differentiated 'parabasal cell dyskaryosis' were found only among the groups with subsequent regression. Those showing dissociated poorly differentiated dyskaryotic parabasal cells regressed to negative in two cases and progressed to invasion in nine. This suggests that many examples of spontaneous regression correspond to mild dysplasias which are not precancerous, and overdiagnosis must often have resulted in unnecessary surgical procedures in the past.

'Regressing' and 'progressing' groups both included cases in which the spatula had removed coherent pieces of undifferentiated epithelium. These are difficult to interpret cytologically. In nine of them (including four which regressed) the cytological picture was that of carcinoma in situ. The remainder (14 cases) were probably examples of reserve cell hyperplasia, and it is noteworthy that, of the 21 cases subsequently progressing to invasive carcinoma, five were preceded by appearances of this type. It is concluded that cell aggregates suggesting an unusual degree of reserve cell hyperplasia are a danger signal and require careful surveillance.

In a nationwide collaborative study of women re-examined after a mean interval of $5 \cdot 2$ years of disappearance or refusal following a 'positive' cervical smear, Kinlen and Spriggs ${ }^{1}$ observed several different outcomes. Out of 52 patients for whom enough information was available, 19 were judged to have lesions which regressed spontaneously, since one or more smears were negative (or else the cervix showed no histological abnormality). In 20 patients, after the interval a biopsy showed some degree of dysplasia or carcinoma in situ. In a further three patients biopsy showed microinvasive carcinoma, and occult or clinical invasive carcinoma had developed in the remaining 10 . Since, to the best of our knowledge, none of these women had had

Received for publication 17 December 1979 any intervening biopsy, cauterisation, or other treatment to the cervix, these outcomes presumably represent the spontaneous course of events.

These conditions are heterogeneous, and, apart from observer variation in classifying a smear as 'positive', there are certainly wide differences from case to case in the cytological features of the smear. We therefore wished to see whether regression or progression were associated with identifiable cytological pictures. The present paper is the result of reviewing the initial 'positive' smears in all patients for whom these were available. Since the lesions eventually classified on biopsy as dysplasia and carcinoma in situ might, if they had not been excised, have been capable of either regression or further progression, a study of their preceding cytological features tells us very little and is not 
analysed here. On the other hand, those lesions which subsequently reverted to 'negative', and those patients subsequently found to have invasive carcinoma, are of the greatest interest, and we have particularly studied these (series 1 and 2).

It was possible to increase the relevant material by examining smears from two other types of case whose spontaneous outcome was known, consisting of 25 cases in which regression occurred within a year, while the patients were under surveillance (series 3), and 10 cases in which invasive squamous carcinoma of the cervix had been preceded at least two years previously by cervical smears not considered 'positive' at the time but showing abnormal cells on review (series 4). The last two series were from the files of the Oxford Laboratory.

\section{Material and methods}

SERIES 1 AND 2

Slides were available for review from 28 cases of the series reported by Kinlen and Spriggs, ${ }^{1}$ viz, 17 examples of regression (series 1) and 11 followed by microinvasive or invasive carcinoma of the cervix (series 2). All of these were studied by AIS, in full knowledge of the subsequent outcome, in the hope of observing features which might have prognostic value. Some of the slides were faded or had been de-stained, but 21 adequate ones, each from a different case, were submitted to MMB with their identification concealed, and he classified them 'blind' according to the degree of severity of the abnormality, using currently accepted criteria. Where several slides were available from the same case, the one with the most severe abnormality was chosen (by AIS) for this experiment.

Subsequently all slides were reviewed by MMB, in the light of the known outcome, and the classification of each case was agreed between the two authors.

\section{SERIES 3}

Twenty-five cases from the Oxford Laboratory files showed conversion from 'positive' to 'negative' smears without any biopsy or surgical interference to the cervix while still under surveillance. In most cases the failure to biopsy was determined by the 'regression' to negative smears.

\section{SERIES 4}

Ten cases were found, also in the files of the Oxford Laboratory, in which invasive cervical carcinoma had been preceded, at least two years previously, by smears which were not reported as positive; but abnormalities were found on review, and these were studied in the light of the subsequent outcome and classified by both authors in collaboration.
For purposes of classification, when several 'positive' slides were available, the one showing the highest grade of abnormality was used.

\section{NOTE ON RELIABILITY}

Our intention has been to study smears from lesions which are definitely known to have regressed or to have become invasive. There is unfortunately an element of uncertainty in both these groups.

Regression has had to be inferred when, after an interval, the smears have become negative. In most cases there have been repeated negative smears, but in five of series 1 and in five of series 3 , it was possible to obtain only one such negative smear, either because of cauterisation following this, or reluctance on the part of the patient or her doctor, or subsequent failure to trace. Some at least of these may be 'false negatives'.

In series 1 there has been no selection in favour of 'false negatives', and the proportion of these should not be unusually high. In series 3 , on the other hand, cases were chosen specifically for the sequence positive $\rightarrow$ negative, and consequently genuine regressions are probably mixed with an unknown proportion in which later smears were false negative, and which entered the series only because the spatula failed to sample a persisting lesion.

That this can easily occur is seen in an analysis of the Oxford figures for the 10 years 1964-73. Of 50 cases where a positive smear was followed by a negative one, 21 came to biopsy; 11 of them showed no significant lesion, but 10 showed either dysplasia or carcinoma in situ.

In the 'progressing' group, those subsequently shown to have microinvasive or invasive carcinoma, we can be nearly sure that the original positive smear came from a lesion which was either malignant already or 'precancerous' in any ordinary sense of the term. But even here there is another possibility. Sections of an affected cervix generally show a variety of different epithelial abnormalities in the same specimen, and the cells originally called 'positive' could have come from a lesion incapable of developing into cancer but which accompanied or was succeeded by a malignant condition.

For the above reasons it cannot be maintained that all the findings in the present series are fully reliable. They do, however, provide better evidence than has been available from 35 years of literature based on cases subjected routinely to biopsy.

\section{CLASSIFICATION OF SMEAR TYPES}

After the re-examination of all slides by both authors, a classification was devised in order to separate categories of prognostic importance. This is not intended to replace existing systems of 
nomenclature but provides a convenient shorthand.

A (Fig. 1) This corresponds to 'superficial cell dyskaryosis' and 'intermediate cell dyskaryosis' in the sense of Papanicolaou, ${ }^{2}$ viz, large, hyperchromatic, irregular nuclei in cells with normal cytoplasmic maturation. This pattern is illustrated in the WHO Atlas, ${ }^{3}$ Figs 72-74 with the caption 'dysplasia, mild'.

B (Fig. 2) Dyskaryosis affecting 'parabasal' cells (with or without admixture of dyskaryotic superficial cells). Although maturation is less advanced than in A, cytoplasm is still adequately developed. Relevant photographs in the WHO Atlas $^{3}$ are Figs 77-81 and 84-85 illustrating 'dysplasia, moderate' and 'dysplasia, severe'.

C (Fig. 3) Undifferentiated cells present, with nuclear enlargement, hyperchromasia, and irregularity. These cells occur free or in small groups. They are shown in the WHO Atlas, ${ }^{3}$ Figs 93, 95, and 105, illustrating 'epidermoid carcinoma in situ'.

D (Fig. 4) Small cornified cells present with marked hyperchromasia of the nuclei, and cytoplasmic aberrations, particularly spindleshaped forms, as shown in the WHO Atlas, ${ }^{3}$ Figs 103 (carcinoma in situ) and 113 and 116, illustrating 'epidermoid carcinoma-keratinising type'.

E (Figs 5 and 6) Undifferentiated epithelial cclls present in coherent masses or sheets. There is a range of appearances from that of simple endocervical reserve cells in regular formations (Fig. 26 of the WHO Atlas ${ }^{3}$ ), through intermediate stages of irregularity and mitotic activity up to that shown in Figs 102 and 108 of the WHO Atlas, ${ }^{3}$ illustrating respectively "carcinoma in situ' and 'carcinoma in situ with microinvasion'. They are not subdivided here because of the lack of prognostic correlation.

\section{Results}

\section{SERIES 1 AND 2 ('DEFAULTERS')}

\section{Blind review of slides}

The set of 21 slides used in this experiment contained 12 from lesions which subsequently regressed and nine from those subsequently shown to have invasive carcinoma. They were arranged 'blind' by MMB in order of apparent severity, without knowing either the identifications or the number of slides in each group. The code was then broken, and a line was

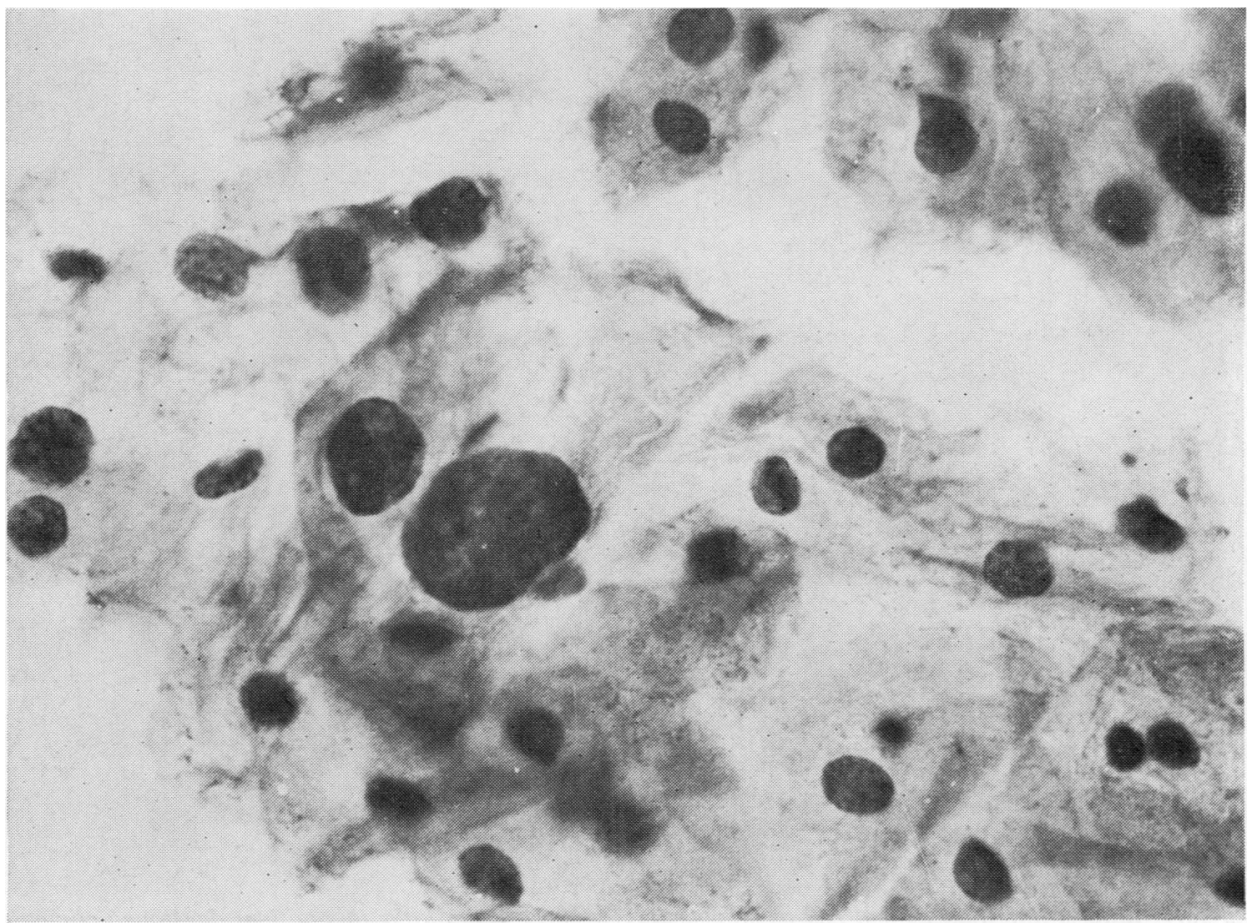

Fig. 1 Superficial cell dyskaryosis (A). Followed by spontaneous regression. Papanicolaou $\times 800$. 


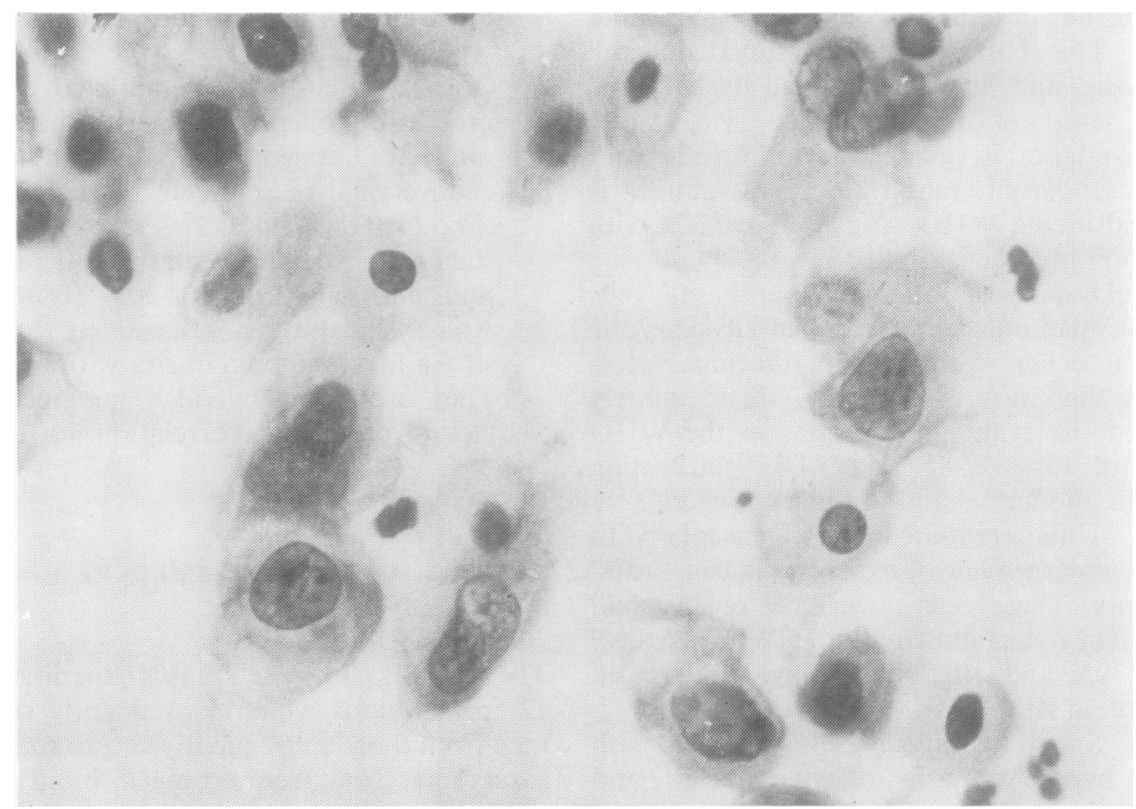

Fig. 2 Well-differentiated parabasal cell dyskaryosis $(B)$. Followed by spontaneous regression. Papanicolaou $\times 800$.

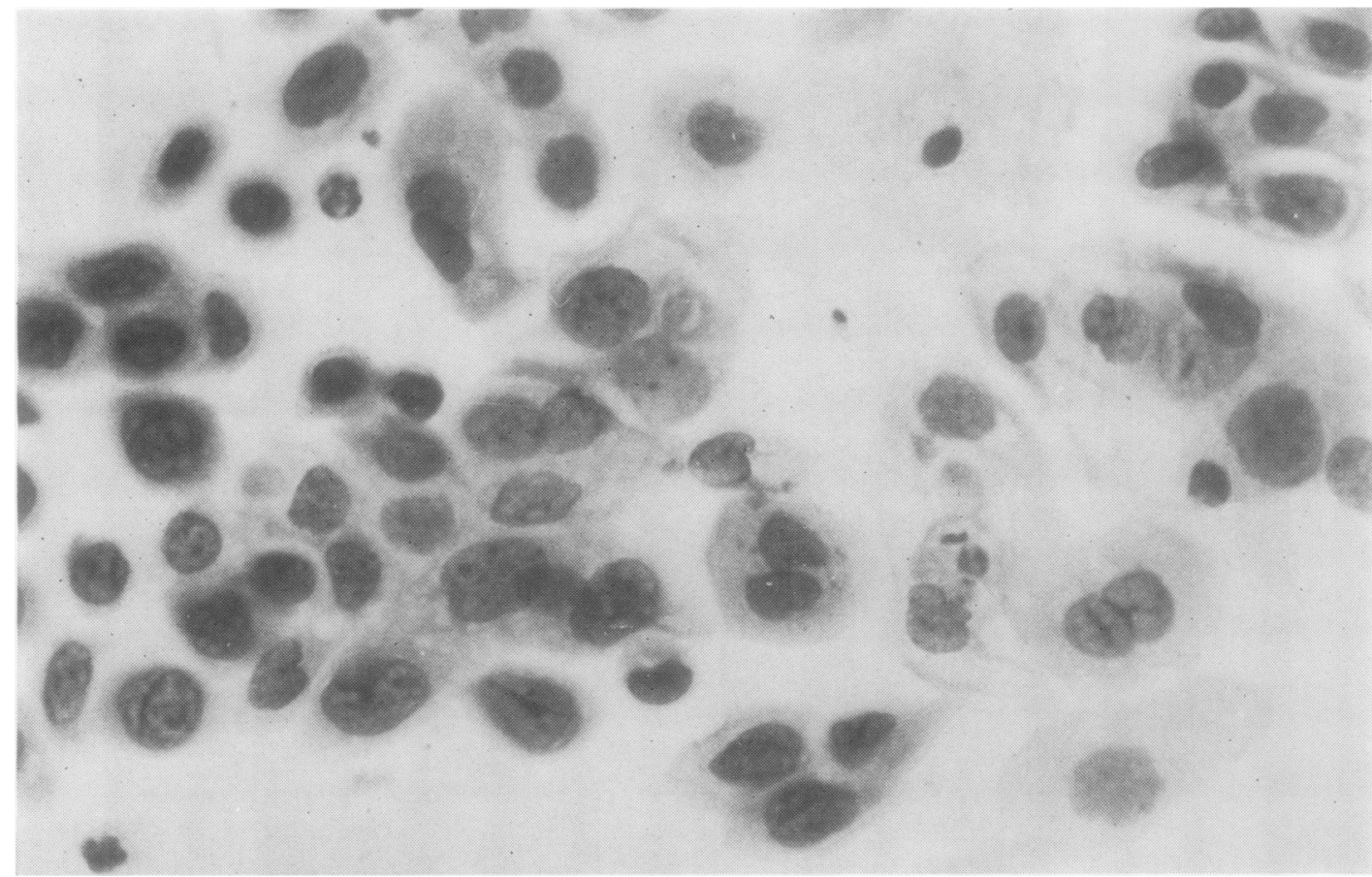

Fig. 3 Poorly differentiated parabasal cell dyskaryosis $(C)$. Three years later this patient developed clinical cervical carcinoma from which she died. Papanicolaou $\times 800$. 


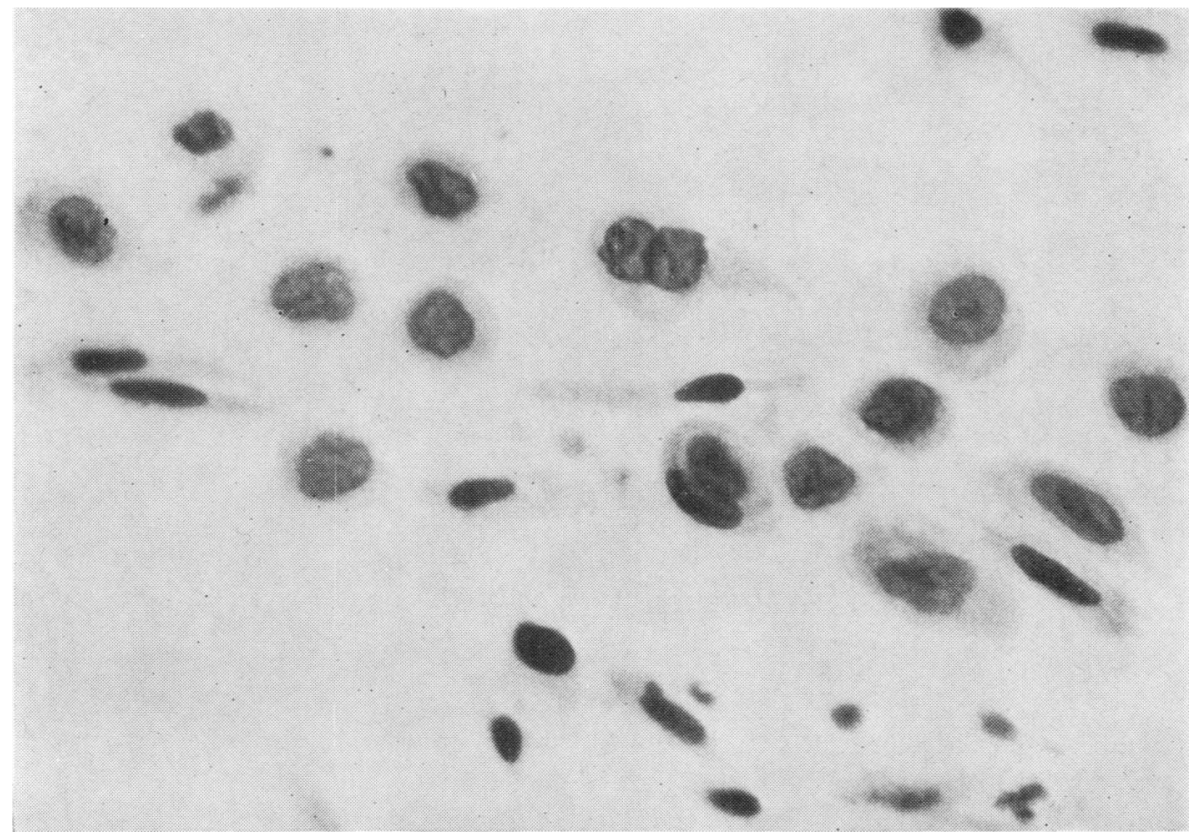

Fig. 4 Parabasal cell dyskaryosis with small hyperchromatic spindle-shaped forms (D). Five years later presented with cervical carcinoma. Papanicolaou $\times 800$.

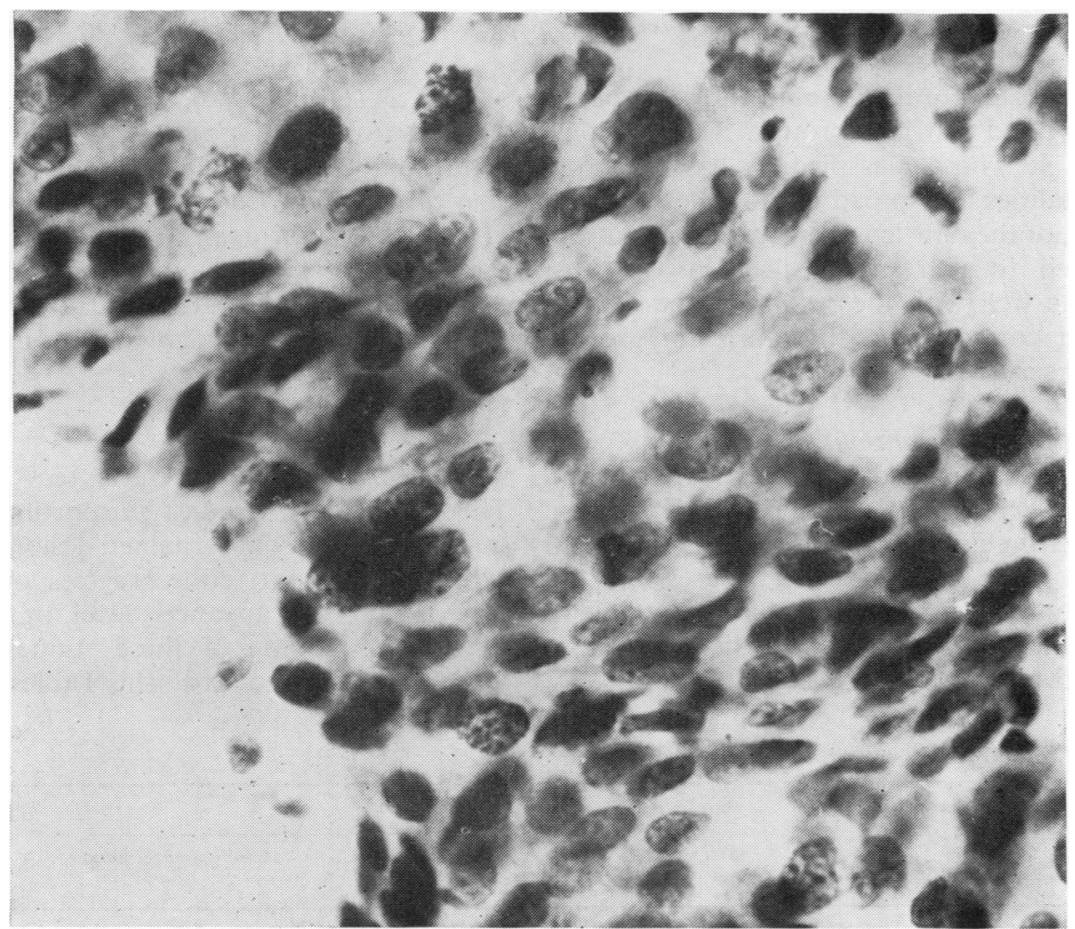

Fig. 5 A coherent epithelial fragment consisting of undifferentiated cells $(E)$, with mitotic activity, suggesting carcinoma in situ. Three and four years later cervical smears were negative. Papanicolaou $\times 800$. 


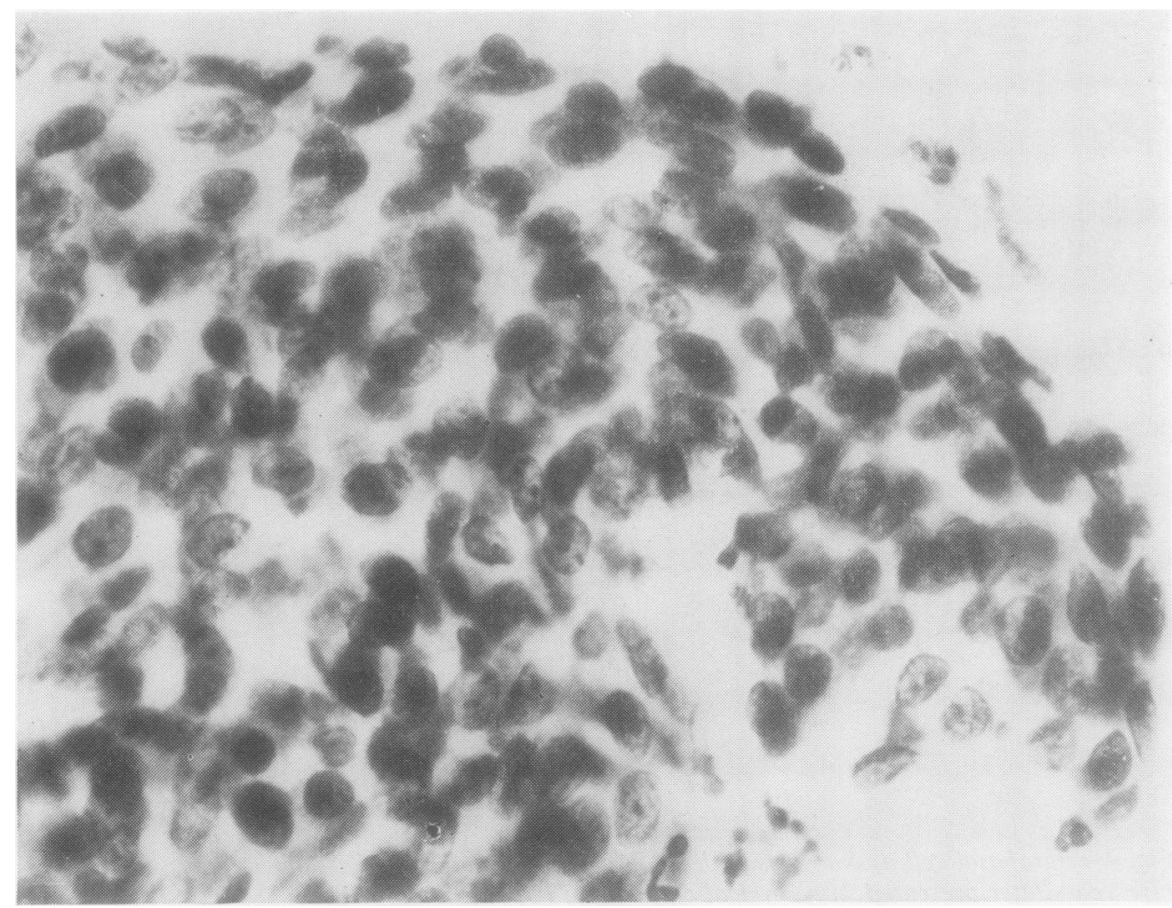

Fig. 6 A coherent fragment consisting of undifferentiated cells $(E)$ presumed to represent reserve cell hyperplasia. Six years later developed squamous carcinoma. Papanicolaou $\times 800$.

drawn at the most favourable level to show a separation into high- and low-risk groups. The result is seen in Table 1. Those classified as having more severe abnormalities are spread among the different outcomes, but, of the nine least severe abnormalities, only one failed to regress. By itself this means little, but it fits well with the results of the rest of this study and confirms that they are not greatly distorted by observer bias.

\section{Review in light of subsequent outcome}

The findings are summarised in Table 2. Apart from the $\mathrm{E}$ category, there is a striking separation between regressions, distinguished by dyskaryosis in welldifferentiated cells, and those progressing to invasive carcinoma (or, possibly, having incipient carcinoma already). The problem of the E category will be referred to later in the Discussion.
SERIES 3 ('POSITIVE' WITH EARLY REGRESSION) AND SERIES 4 ('FALSE NEGATIVE' SMEARS PRECEDING CLINICAL CARCINOMA) The contrast between these two series may be seen in Table 3. Once again, all those classified as well differentiated are found among the regressions, and again the $\mathrm{E}$ category did not regularly specify either regression or progression to invasion.

\section{Discussion}

\section{REGRESSION AND PROGRESSION}

There are many studies purporting to show the frequency with which named lesions (dysplasia or carcinoma in situ) either regress or proceed to a supposedly more advanced level, or, in a few series, to invasion. Some of these studies are listed by Patten ${ }^{4}$ and by Burghardt ${ }^{5}$ (his Tables 1-3). A detailed

Table 1 'Defaulters' slides read blind

\begin{tabular}{|c|c|c|c|c|c|}
\hline & \multirow[t]{2}{*}{ Regression } & \multicolumn{3}{|l|}{ Outcome } & \multirow[t]{2}{*}{ Total } \\
\hline & & $\begin{array}{l}\text { Microinvasive } \\
\text { carcinoma }\end{array}$ & Occult carcinoma & Clinical carcinoma & \\
\hline Least severe & 8 & 1 & - & $\bar{\varepsilon}$ & 9 \\
\hline Most severe & 4 & 2 & 1 & 5 & 12 \\
\hline
\end{tabular}


Table 2 'Defaulters' series

\begin{tabular}{|c|c|c|}
\hline & Series I & Series 2 \\
\hline & Regressed & $\begin{array}{l}\text { Progressed to } \\
\text { invasive carcinoma }\end{array}$ \\
\hline A Superficial dyskaryosis & 6 & 0 \\
\hline$A$ and $B$ & 4 & 0 \\
\hline $\begin{array}{l}\text { B Parabasal dyskaryosis } \\
\text { well differentiated }\end{array}$ & 2 & 0 \\
\hline $\begin{array}{l}\text { C Parabasal dyskaryosis } \\
\text { poorly differentiated }\end{array}$ & 1 & 7 \\
\hline $\begin{array}{l}\text { D Irregular small neoplastic } \\
\text { cells with cornification }\end{array}$ & 0 & 2 \\
\hline $\begin{array}{l}\text { E Aggregates of } \\
\text { undifferentiated cells }\end{array}$ & 4 & 2 \\
\hline Total & 17 & 11 \\
\hline
\end{tabular}

Table 3 Oxford series

\begin{tabular}{|c|c|c|}
\hline & Series 3 & Series 4 \\
\hline & $\begin{array}{l}\text { 'Positive' with } \\
\text { early regression }\end{array}$ & $\begin{array}{l}\text { 'False negative' } \\
\text { (preceding invasive } \\
\text { carcinoma) }\end{array}$ \\
\hline A Superficial dyskaryosis & 12 & 0 \\
\hline$A$ and $B$ & 2 & 0 \\
\hline $\begin{array}{l}\text { B Parabasal dyskaryosis } \\
\text { well differentiated }\end{array}$ & 1 & 0 \\
\hline $\begin{array}{l}\text { C Parabasal dyskaryosis } \\
\text { poorly differentiated }\end{array}$ & 1 & 2 \\
\hline $\begin{array}{l}\text { D Irregular small neoplastic } \\
\text { cells with cornification }\end{array}$ & 0 & 0 \\
\hline $\begin{array}{l}\text { E Aggregates of } \\
\text { undifferentiated cells }\end{array}$ & 9 & 8 \\
\hline Total & 25 & 10 \\
\hline
\end{tabular}

analysis is not particularly revealing because of the well-known variations in use of the names 'dysplasia' and 'carcinoma in situ' and the fact that most of the observations have been made on lesions followed by punch biopsies, which certainly interfere with the course of the disease. ${ }^{6} 7$ Almost the only studies in which biopsy was avoided are those confined to 'dysplasia', which was not deliberately allowed to progress beyond the stage of carcinoma in situ; these studies show, at least, that many lesions classified cytologically as 'dysplasia' are capable of spontaneous regression. Estimates of the frequency of this occurrence vary widely; Stern and Neely ${ }^{8}$ estimated that dysplasias regress at the rate of $35 \%$ per annum, whereas, according to Richart and Barron, ${ }^{9}$ regression is uncommon and occurs only in the mildest lesions. These differences doubtless reflect differences in terminology.

Progression to invasive carcinoma has been observed repeatedly in cases showing carcinoma in situ in a previous biopsy, and indeed this is the main evidence for believing that carcinoma in situ is genuinely precancerous, but published series do not provide a reliable idea of the probability of progression. Biopsy or its subsequent healing process may result in disappearance of the lesion, while, on the other hand, those apparently progressing may have had invasion already at the time of the original biopsy, which failed to sample the relevant point. Hence studies such as those of Petersen, ${ }^{10}$ suggesting that $30-40 \%$ of cases of carcinoma in situ progress to invasion, may greatly over- or under-estimate the true figure.

The most widely held opinion, formed from accumulated evidence of varying validity over the last 25 years, is that there is a sequence of development from mild to severe dysplasia, carcinoma in situ, microinvasive carcinoma, and, finally, full invasion, and that regression is common in mild dysplasia but rare in carcinoma in situ. The latter is generally thought to be a committed precursor of invasive squamous cancer. ${ }^{11}$

The recent analysis of the follow-up of 'defaulters'1 did not address the question of the separate behaviour of dysplasia or of carcinoma in situ, since no biopsy diagnosis was made before the patients escaped from surveillance. Of those women permitting further smears, $32 \%$ had apparent regression of their lesions; and of the whole series, whether traced or not, $13 \%$ were eventually shown to have microinvasive or invasive carcinoma. If those not found, or refusing further smears, are excluded from the denominator, the figure for 'progression' becomes $22 \%$ (in five years).

It is therefore of critical importance to see whether the smears from lesions which regressed are distinguishable from those which progressed to cancer (or already had invasive cancer at the start). If they are different, this may well mean that certain dysplasias represent a different and unrelated condition rather than an early and still reversible stage of neoplasia. There is some epidemiological evidence for this. ${ }^{12} 13$

\section{SMEAR PATTERN AND PROGNOSIS}

(A) The pattern which Papanicolaou ${ }^{2}$ called 'superficial cell dyskaryosis' is well known to correspond to the histological picture of mild dysplasia or, in the terminology of Richart, ${ }^{914}$ 'CIN (cervical intraepithelial neoplasia) grade I'. This picture, or some variant of it, was shown in 10 of the cases in series 1 which regressed, and in 14 of those in series 3 . In contrast, it was seen in only three of the cases which subsequently developed carcinoma and then was associated with other cells of more sinister significance.

Evidently most of these lesions are not neoplastic at all, and recent opinion incriminates the virus of genital warts in some of them. ${ }^{15} \mathrm{~A}$ transition from the cytological picture corresponding to mild dysplasia into that of carcinoma in situ has, how- 
ever, been observed ${ }^{9}$ and photographically documented $^{1617}$, so that some association between the two conditions seems to exist even if it is not of great clinical importance.

It may therefore be concluded that many of the cases in series 1 and 3 represent 'overdiagnosis', and with a more conservative reporting policy some unnecessary surgery could have been avoided.

(B and C) Dyskaryosis of 'parabasal' or immature squamous metaplastic cells has a different significance. This is the cytological reflection of moderate or severe dysplasia or carcinoma in situ. Naturally there are varying degrees of severity, from mild atypia in immature squamous metaplastic cells up to either complete anaplasia (in carcinoma in situ) or to pictures suggesting the onset of differentiating squamous carcinoma. We have separated those with more and less differentiation as categories B and C respectively.

Among the cases with regressing lesions (series 1 and 3), only two were classified as showing parabasal cell dyskaryosis with poor differentiation, one case in each series. In the cases which subsequently showed invasion or microinvasion (series 2 and 4), parabasal cell dyskaryosis was one of the most common patterns, occurring altogether in nine, all of which appeared severe. From the evidence of this series we cannot draw a reliable line to separate all those which regress from all those to be followed by cancer, but in the poorly differentiated group (C) regression is evidently an unusual event, and persistence or progression is to be expected.

(D) Cornified cells with irregular cytoplasm and nuclear hyperchromasia have often been described and illustrated as a feature of incipient (as well as established) squamous carcinoma. In series 2 there was one case with fibre- or spindle-shaped squamous cells, and another with a large-cell variant of this picture. It may be believed that these two patients had invasive carcinoma already at the time of sampling, 4 years and 5 years before clinical cancer. (E) Coherent masses of undifferentiated cells provide one of the most troublesome problems in the cytological assessment of cervical smears. They also provide some of the most interesting findings in the present group of cases.

Among the patients in whom regression occurred, series 1 provides four examples of 'microbiopsies' in which nuclear irregularities led to 'positive' reports. The oldest of these four was aged 35. Two of them on review seem to show the rather typical picture of carcinoma in situ as illustrated by Tweeddale and Dubilier ${ }^{18}$ (Fig. 10-1), Riotton and Christopherson, ${ }^{3}$ (Figs 102 and 108), Grubb ${ }^{19}$ (Fig. 16.2), and Patten ${ }^{4}$ (Fig. 223). A field from one of these two cases is shown in Figure 5
Similarly, in series 3 , nine cases showed actual epithelial fragments; seven of these (three of which were postmenopausal) seem to be examples of irregular hyperplasia of endocervical epithelium due to inflammation or repair, or of simple reserve cell hyperplasia, but two of them (aged 50 and 51) are indistinguishable from the picture of carcinoma in situ as seen in 'microbiopsies' spread out in smears. There seem, therefore, to be four cases in which this type of lesion, which some authorities consider irreversible, has regressed without interference. The number of negative smears obtained were one and two respectively in the series 1 cases, and in the series 3 cases, three and nine. These last two both underwent endometrial curettage in the interval but no interference with the cervix other than dilatation.

Unusual cell sheets were also seen in 10 of the patients later developing carcinoma. All were aged over 35. In five of them these consisted of pieces of detached epithelium with enlarged anaplastic nuclei, expected to represent carcinoma in situ. The remaining five are of great interest, since they may reveal a relatively common precancerous sequence which is not usually emphasised in texts on cytological diagnosis, viz, reserve cell hyperplasia developing directly into carcinoma in situ without any recognisable squamous differentiation.

In these cases, masses of rather regular undifferentiated cells were seen, almost resembling endometrium but evidently detached from the cervix by the spatula (Fig. 6). They showed no columnar cell layer on the superficial aspect, and orientation was often impossible. Three of these cases were postmenopausal.

Reagan and Hicks ${ }^{20}$ proposed that the 'undifferentiated type of in situ cancer' developed from a multilayered epithelium consisting of subcolumnar reserve cells, and they presented photographs illustrating this 'anaplastic metaplasia' found contiguous to classical carcinoma in situ. According to de Brux and Dupré-Froment, ${ }^{21}$ 'certain immature carcinomas, in fact, are devoid of anomalies and on the smear show patches of a monomorphous aspect'; accordingly, it was difficult to draw the line cytologically between reserve cell hyperplasia and carcinoma in situ. Patten ${ }^{4}$ writes that the small-cell type of carcinoma in situ presents 'as looselyarranged syncytial masses of relatively small cells', and this type is supposed to originate from reserve cells directly. Photographs of the histological progression from 'subcylindrical cell anaplasia' or abnormal reserve cell proliferation to carcinoma in situ have been published by several authors, 52223 and recently Christopherson ${ }^{24}$ and Beyer-Boon and Verdonk $^{25}$ have emphasised the view that some 
carcinoma in situ may have its origin in 'reserve cell dysplasia' or 'atypical reserve cells' as well as in the more usual squamous dysplasia (which may also, ultimately, be traced back to reserve cell proliferation).

As a histological entity, some degree of reserve cell hyperplasia is common. Nevertheless, as Patten ${ }^{4}$ writes, 'as compared to the frequency with which cells originating from squamous metaplasia are observed, those coming from reserve cell hyperplasia are relatively rare in routine cellular samples'. The cytological picture which we have described is not particularly common, and the cases found by screening are not too numerous to be placed in a high-risk category. Since it appears from the present series that they may develop invasive carcinoma in later years, we consider that such patients should be followed with particular care. This may be a more important condition to detect than the milder squamous dysplasias, which constitute the bulk of the abnormalities found in screening young women, and which in most cases are probably only remotely related to neoplasia.

We are very grateful to the following colleagues who lent us slides for use in this study: Dr A Ambery Smith, Dr EB Butler, Dr CM Davidson, Dr SW Davies, Dr HLD Duguid, Dr AT Edwards, Mr R Goulden, Dr RS Kirk, Miss R McBryde, Dr A MacFarlane, Dr EFD Mackenzie, Dr D MacKinnon, Dr SMD McNair, Dr JH Rack, Dr KJ Randall, and Dr HR Wilson.

\section{References}

${ }^{1}$ Kinlen LJ, Spriggs AI. Women with positive cervical smears but without surgical intervention. A follow-up study. Lancet 1978;2:463-5.

2 Papanicolaou GN. Atlas of Exfoliative Cytology. Cambridge, Mass: Harvard University Press, 1954.

${ }^{3}$ Riotton G, Christopherson WM. Cytology of the Female Genital Tract. International Histological Classification of Tumours No.8. Geneva: WHO, 1973.

4 Patten SF. Diagnostic Cytopathology of the Uterine Cervix, 2nd ed. Basle: Karger, 1978.

${ }^{5}$ Burghardt E. Early Histological Diagnosis of Cervical Cancer. Philadelphia: Saunders, 1973.

${ }^{6}$ Koss LG, Stewart FW, Foote FW, Jordan MJ, Bader GM, Day E. Some histological aspects of behavior of epidermoid carcinoma in situ and related lesions of the uterine cervix. Cancer 1963; 16:1160-211.

${ }^{7}$ Richart RM. Influence of diagnostic and therapeutic procedures on the distribution of cervical intraepithelial neoplasia. Cancer 1966;19:1635-8.
${ }^{8}$ Stern E, Neely PM. Dysplasia of the uterine cervix. Incidence of regression, recurrence and cancer. Cancer 1964;17:508-12.

${ }^{9}$ Richart RM, Barron BA. A follow-up study of patients with cervical dysplasia. Am J Obstet Gynecol 1969;105:386-93.

${ }^{10}$ Petersen O. Precancerous changes of the cervical epithelium. Acta Radiol 1955; suppl 127.

${ }^{11}$ Christopherson WM. Concepts of genesis and development in early cervical neoplasia. Obstet Gynecol Surv 1969;24:842-50.

12 Thomas DB. An epidemiologic study of carcinoma in situ and squamous dysplasia of the uterine cervix. Am J Epideriol 1973;98:10-28.

${ }^{13}$ Thomas DB, Rawls WE. Relation of herpes simplex virus Type 2 antibodies and squamous dysplasia to cervical carcinoma in situ. Cancer 1978;42:2716-25.

${ }^{14}$ Koss LG. Dysplasia. A real concept or a misnomer? Obstet Gynecol 1978;51:374-9.

${ }^{15}$ Meisels A, Fortin R. Condylomatous lesions of the cervix and vagina. I Cytologic patterns. Acta Cytol (Baltimore) 1976;20:505-9.

${ }^{16}$ Lerch V, Okagaki T, Austin JH, Kevorkian AY, Younge PA. Cytologic findings in progression of anaplasia (dysplasia) to carcinoma in situ: a progress report. Acta Cytol (Philadelphia) 1963;7:183-6.

${ }^{17}$ Koss LG. Diagnostic Cytology and its Histopathologic Bases, 2nd ed. Philadelphia: Lippincott, 1968.

18 Tweeddale DN, Dubilier LD. Cytopathology of Female Genital Tract Neoplasms. Chicago: Year Book Publishers, 1972.

${ }^{19}$ Grubb C. Colour Atlas of Gynaecological Cytopathology. Aylesbury: HM \& M Publishers, 1977.

${ }^{20}$ Reagan JW, Hicks DJ. A study of in situ and squamouscell cancer of the uterine cervix. Cancer 1953;6: 1200-14.

${ }^{21}$ de Brux J, Dupré-Froment J. Exfoliative cytology of reserve cell hyperplasia, basal cell hyperplasia and dysplasia. Acta Cytol (Philadelphia) 1961;5:142-9.

22 Johnson LD, Easterday CL, Gore H, Hertig AT. The histogenesis of carcinoma in situ of the uterine cervix. A preliminary report of the origin of carcinoma in situ in subcylindrical cell anaplasia. Cancer 1964;17:213-29.

${ }^{23}$ Reagan JW, Seidemann IB, Patten SF, Jr. Developmental stages of in situ carcinoma in uterine cervix: an analytical study of the cells. Acta Cytol (Philadelphia) 1962;6:538-46.

${ }^{24}$ Christopherson WM. Dysplasia, carcinoma in situ, and microinvasive carcinoma of the uterine cervix. Hum Pathol 1977;8:489-501.

${ }^{25}$ Beyer-Boon ME, Verdonk GW. The identification of atypical reserve cells in smears of patients with premalignant and malignant changes in the squamous and glandular epithelium of the uterine cervix. Acta Cytol (Baltimore) 1978;22:305-11.

Requests for reprints to: Dr AI Spriggs, Laboratory of Clinical Cytology, The Churchill Hospital, Headington, Oxford OX3 7LJ, UK. 